\title{
MERCADO DE TRABALHO DE ARQUIVOLOGIA NO BRASIL: ANÁLISE DE ANÚNCIOS DE EMPREGO NA WEB*
}

\begin{abstract}
Resumo: O presente artigo é resultado de pesquisa, realizada pra conclusão de curso em Arquivologia, que buscou descrever o campo de atuação profissional dos arquivistas no Brasil utilizando como dados os anúncios de empregos em site na web. Objetivou-se reunir o corpus de ofertas de trabalho do portal empresarial Catho durante o período da pesquisa, identificar tendências de contratação por parte das organizações e apresentar as habilidades e competências requisitadas a esses profissionais. Através do método quanti-qualitativo foi possível identificar: a distribuição de anúncios por mês, a divisão demográfica das vagas no território brasileiro, o nível de capacitação exigido, as habilidades e competências requeridas, as atividades a serem realizadas, o regime de contratação, a remuneração e os benefícios das vagas anunciadas. Concluiu-se que o campo de trabalho para arquivistas encontra-se em expansão como reflexo de uma sociedade com o crescimento informacional acelerado frente às novas tecnologias. As habilidades e competências profissionais requisitadas são específicas e demandam capacitação por parte desses profissionais, seja durante a graduação ou por meio de educação continuada.
\end{abstract}

Palavras-chave: Arquivistas. Mercado de trabalho. Habilidades e competências. Formação profissional. Brasil.
Rafael Oda

Mestrando no Programa de Pós-Graduação em Ciência da Informação da Universidade Federal de Santa Catarina (PGCIN/UFSC) rafaeloda@outlook.com.br

Eliana Maria dos Santos Bahia Jacintho Doutora em Biblioteconomia e Documentação pela Universidade Carlos III. Professora da Universidade Federal de Santa Catarina (UFSC) elianambahia@gmail.com

\section{ARCHIVOLOGY LABOR MARKET IN BRAZIL: WEB EMPLOYMENT ANALYSIS ANALYSIS}

\begin{abstract}
This article is the result of research, carried out for the conclusion of a course in Archivology, which sought to describe the field of professional activity of the archivists in Brazil using as data the ads of jobs on the web site. The objective was to gather the corpus of job offers from the Catho business portal during the period of the survey, to identify contracting trends by organizations and to present the skills and competencies required of these professionals. Through the quantitative-qualitative method, it was possible to identify: the distribution of advertisements per month, the demographic division of the vacancies in Brazil, the level of qualification required, the skills and competencies required, the activities to be performed, the hiring regime, remuneration and benefits of announced vacancies. It was concluded that the field of work for archivists is expanding as a reflection of a society with accelerated informational growth in relation to new technologies. The requisite professional skills and competencies are specific and require training by these professionals, either during graduation or through continuing education.
\end{abstract}

Keywords: Archivists. Job market. Skills and competences. Professional qualification. Brazil.

\footnotetext{
* Pesquisa realizada e aprovada para a obtenção do título de Bacharel em Arquivologia pela Universidade Federal de Santa Catarina e orientada pela Dra. Eliana Maria dos Santos Bahia Jacintho
} 


\section{INTRODUÇÃO}

O campo de trabalho para arquivistas encontra-se em desenvolvimento no Brasil. E, embora não seja uma relação exclusiva, a expansão deste mercado de trabalho é um reflexo das necessidades de um mundo marcado pela produção informacional acelerada.

A competitividade e a necessidade de informações qualificadas, que sejam recuperadas prontamente, que racionalizem as ações tomadas e possibilitem a redução de custos para as organizações, demostram a necessidade de profissionais que tratem diretamente a informação. Consistindo o arquivista em um desses profissionais, e tendo em vista a função estratégica que os documentos exercem nos processos organizacionais, torna-se possível investigar sua atuação nas organizações através de diagnósticos como o realizado na pesquisa que resultou no presente artigo.

Com a globalização e a crescente velocidade na troca de informações, bem como as oportunidades acadêmicas e profissionais que se abrem, diagnosticar o mercado de trabalho passa a ter destaque para o arquivista, para as universidades e para o próprio mercado - que se inspiram, se adequam e se aprimoram de forma mais ampla, eficaz e abrangente. E é na demanda por profissionais capazes e atualizados no que diz respeito ao tratamento da informação que se verifica a relação entre universidade e sociedade.

São indissociáveis universidade, arquivistas, sociedade, e suas consequências relacionais para a atuação desses profissionais. Da mesma forma, a caracterização do ambiente de trabalho do arquivista e as competências solicitadas para a sua atuação caminham juntas. Esta caracterização auxilia a capacitação das universidades para que a formação atenda às demandas da sociedade. No entanto, estas demandas não são atendidas exclusivamente por profissionais e graduandos em Arquivologia, que concorrem com outros profissionais que vêm ocupando seus postos de trabalho - não só no ambiente prospectivo como até mesmo no convencional. Assim, entender e participar da construção do mercado de trabalho influencia na valorização da Arquivologia e do arquivista.

Desta forma, este artigo apresenta uma revisão sobre o portal empresarial Catho e os resultados obtidos em sua base de dados, utilizando para tanto o corpus de ofertas de trabalho do site, permitindo caracterizar o mercado de trabalho do arquivista no Brasil durante o período pesquisado. 


\section{ARQUIVOLOGIA E O MERCADO DO TRABALHO}

A Arquivologia é vista como uma profissão da contemporaneidade, porém sabe-se através da evolução histórica dos arquivos que os profissionais responsáveis pela documentação de uma organização já eram identificados desde as civilizações antigas. No Egito Antigo, por exemplo, a tarefa de autentificar e de conservar os documentos era confiada a um funcionário do Estado. (GAGNON-ARGUIN, 1998) E mais do que a evolução histórica dos arquivos, as mudanças no cenário global afetaram, também, o comportamento das sociedades no que diz respeito ao trabalho. A partir da sociedade industrial, novas estratégias de racionalização e redução de custos foram introduzidas como reflexo de uma maior competitividade, tendo consequências na atuação de profissionais no mercado de trabalho. (SANTANA, 2005).

Das civilizações antigas aos dias contemporâneos, nota-se que a informação vem sendo tratada como estratégica. Na atualidade, a informação é peça chave na gestão de uma organização e em seu cotidiano. Essa relevância decorre da necessidade, em todo o processo administrativo, de possibilitar mais clareza e discernimento nas ações tomadas em uma organização. Este papel articuloso reflete na valorização da informação e do profissional e, sobretudo em uma gestão documental eficaz, que permita a recuperação rápida de informações e possibilite a racionalização na tomada de decisão.

E junto das mudanças sociais, econômicas e comportamentais, emergem as legislações específicas. A gestão documental, parte integrante da gestão da informação, é instituída no Brasil através da Lei $\mathrm{N}^{\mathrm{o}} 8.159$, de 8 de janeiro de 1991, como o "conjunto de procedimentos e operações técnicas referente à sua produção, tramitação, uso, avaliação e arquivamento em fase corrente e intermediária, visando a sua eliminação ou recolhimento para guarda permanente". Em outras palavras, trata-se do conjunto de atividades que têm como objetivo solucionar problemas organizacionais relacionados à documentação, a tornar possível o fluxo de informações e a auxiliar o processo administrativo de uma organização.

No que se refere ao profissional que atua nestes contextos, sua demanda marca o crescimento de cursos relacionados. Entre estes, se encontra o curso de Arquivologia responsável pela formação do arquivista, profissional reconhecido no Brasil pela Lei $\mathrm{N}^{\mathrm{o}}$ 6.546, de 4 de julho de 1978 e cuja atuação é regulamentada pelo Decreto No 82.590, de 6 de novembro de 1978.

Com o objetivo de identificar a demanda por esses profissionais no Brasil, pensando na inserção no mercado de trabalho, foi realizada a pesquisa para a obtenção do título de 
Bacharel em Arquivologia pela Universidade Federal de Santa Catarina, cujos resultados são neste artigo apresentados. Este estudo possibilitou um diagnóstico do atual mercado de trabalho, identificando competências e habilidades exigidas e possibilitando o auxílio e estímulo de estudantes em buscá-las durante a formação. Ao conhecer o atual mercado de trabalho do arquivista torna-se possível realizar prognósticos quanto ao futuro da profissão informações essas que fundamentam a possibilidade de mudanças curriculares nos cursos de graduação e na oferta e busca por educação continuada.

\section{CAMINHOS METODOLÓGICOS E O PORTAL CATHO}

A facilidade de acesso e coleta de dados contribuem para que o uso de páginas web para a extração de anúncios de emprego no Brasil seja universo para pesquisas desse tipo. Estudos como de Moreiro Gonzalez e Vergueiro (2012); Moreiro Gonzalez, Vergueiro e Sánchez-Cuadrado (2012); Bahia (2016) e Bahia e Moreiro (2014 e 2019) utilizam metodologia semelhante com enfoque nesses portais.

Estes estudos demonstram a confiabilidade da fonte de pesquisa: o portal empresarial Catho - uma empresa de tecnologia voltada à classificação online de currículos e vagas de empregos que possui mais de 7 milhões de currículos cadastrados, dos quais, 4 mil novos por dia. (CATHO, 2018) A qualificação e a dimensão do portal contribuíram para a escolha da base de dados para a pesquisa aqui apresentada, que possuiu natureza aplicada, através da descrição das características de demandas do mercado de trabalho em Arquivologia no Brasil, tendo sido realizada no período de setembro de 2017 a abril de 2018.

Os procedimentos metodológicos, por sua vez, estabeleceram uma abordagem de natureza qualitativa e quantitativa, com pesquisa documental nos anúncios de emprego da plataforma e, análise de dados.

Os procedimentos quantitativos dos resultados coletados da plataforma Catho objetivaram caracterizar as ofertas de emprego. Optou-se por utilizar o termo de busca "arquivista" ao notar-se que a plataforma recuperava os resultados que tivessem relação direta com as atividades executadas por este profissional. Dos 164 anúncios recuperados, 76 deles possuíam como título para o cargo o termo "arquivista", 40 deles foram de "auxiliar de arquivo" e 7 de "supervisor de arquivo". Os 41 anúncios restantes representaram títulos diversificados, entre os quais, alguns genéricos e que não caracterizam o profissional em sua complexidade, 
como por exemplo, "auxiliar de escritório". Filtros não foram utilizados e o método de ordenação das informações foi o cronológico.

\section{ANÁLISE E DISCUSSÃO DOS RESULTADOS}

A coleta de dados ocorreu no portal empresarial Catho, no período de setembro de 2017 a abril de 2018, e totalizou 7 meses e 4 dias. Os dados foram processados à medida que foram coletados e seus resultados finais são aqui apresentados, organizados por subseções que abordam os conjuntos identificados: anúncios por mês, divisão demográfica das vagas, nível de capacitação, habilidades requeridas, competências exigidas, atividades a serem executadas, regime de contratação, benefícios e remuneração.

\subsection{ANÚNCIOS POR MÊS}

Com o objetivo de identificar o comportamento do mercado de trabalho brasileiro atual, o processamento de dados teve como ponto de partida o número de anúncios de emprego em cada mês do período de coleta. Foram recuperados 164 anúncios durante este período, porém setembro, com apenas 1 anúncio, foi desconsiderado tendo em vista que a coleta não contemplou o mês inteiro, sendo iniciada em seus últimos dias.

Constatou-se que o mês de janeiro apresentou 38 anúncios, representando o maior número com $23 \%$ do total. Esse dado sugere a necessidade das organizações começarem o ano com a aplicação de novas políticas e na busca por profissionais competentes na hora de gerir o acervo documental. Dezembro, não muito atrás, com 30 anúncios e $18 \%$ do total, sugere que as empresas começam a pensar previamente na contratação de arquivistas e em melhorias para o ano seguinte.

Abril e novembro apresentaram respectivamente 25 e 24 anúncios e foram representados com $15 \%$ das incidências. Fevereiro teve 21 anúncios cadastrados e $13 \%$ das incidências. Com as menores incidências, o mês de Março e Outubro, com 16 e 9 anúncios, representados com $10 \%$ e $6 \%$.

Verificar a distribuição de vagas por meses do ano não se trata de simples curiosidade, mas possibilita quais os melhores meses para a busca de uma vaga de emprego na área. Por padrão, os arquivistas obtém seus títulos de graduação em dois períodos do ano, desta forma, 
necessita-se atenção na hora de buscar uma futura vaga no mercado de trabalho. Independente do mês de busca sabe-se que vagas existem, no entanto nos meses de janeiro e dezembro a busca por profissionais desta área é maior, com uma ampla gama de opções e a possibilidade de comparação de vagas proporciona uma escolha que atenda às qualificações do futuro empregado.

\subsection{DIVISÃO DEMOGRÁFICA DAS VAGAS}

O comportamento dos anúncios não consiste apenas na data em que foram anunciados, mas outros pontos também auxiliam na caracterização do mercado de trabalho. A divisão demográfica das vagas sugere quais regiões do Brasil possuem o maior número delas. Como esperado, as capitais dos Estados tendem a possuir mais oportunidades de emprego por, muitas vezes, constituírem os locais com o maior número de empresas, instituições e organizações no Estado.

A região Sudeste do Brasil foi a que teve o maior número de incidências, com 118 anúncios e $72 \%$ do total. O Estado de São Paulo, situado nesta região, teve 82 incidências e compõe 49,32\% dos anúncios. Sua capital, o município de São Paulo, caracterizado como uma grande metrópole que comporta múltiplas organizações dos diversos ramos de atuação, teve por si só 57 incidências. Destacam-se ainda os Estados de Rio de Janeiro e Minas Gerais, que tiveram cada um deles 18 anúncios, com o maior número de incidências nas suas respectivas capitais Rio de Janeiro com 16 e Belo Horizonte com 12, compondo cada um desses estados $11 \%$ do total.

A região Sudeste constituída pelos Estados de Espírito Santo (sem nenhuma incidência), Minas Gerais, Rio de Janeiro e São Paulo (previamente comentados) possuem o maior número de incidências sendo responsável por quase $3 / 4$ das vagas anunciadas no portal Catho no período pesquisado.

As demais regiões tiveram resultados bastante inferiores no que se refere ao número de vagas anunciadas quando comparadas com a região sudeste. A segunda região com maior número de incidências foi à região Sul, com o número de 18 e $11 \%$, das quais 10 delas no Estado do Paraná, 6 no Rio Grande do Sul e 2 em Santa Catarina. Percebe-se que o número de anúncios da região Sul é o mesmo de apenas um dos Estados do Sudeste - tanto Rio de Janeiro quanto Minas Gerais tiveram cada um 18 incidências. 
Em menor incidência ainda, Centro-Oeste, Nordeste e Norte respectivamente com 15, 10 e 3 anúncios. Juntas estas três Regiões constituem 17\% das vagas anunciadas durante o período pesquisado.

Constatar a divisão demográfica das vagas possibilita uma noção prévia da necessidade de locomoção para outra cidade, Estado ou região do país para ingresso em emprego de arquivista. Observou-se nesta pesquisa que as capitais dos Estados são as zonas que mais possuem empregos na área em questão. Ressalta-se, assim, o papel do marketing profissional e da conscientização das empresas para a consolidação do mercado já existente e para a possibilidade de abertura de novos postos de trabalho em outras partes do Brasil.

O município de São Paulo apresenta um comportamento distinto ao ser comparado com outras cidades brasileiras. A cidade possui um total de $34,8 \%$ dos anúncios no portal empresarial Catho, como reflexo do grande número de empresas, instituições e organizações presentes no maior centro urbano brasileiro. Um destaque que deve ser abordado aqui é a localização geográfica das universidades que ofertam cursos de graduação em Arquivologia, segundo o CONARQ (2018), as regiões sul e sudeste possuem 5 cursos de graduação cada uma, nordeste 3 , norte 2 e centro-oeste 1 - o que demonstra de forma prática as relações entre sociedade, informação, mercado de trabalho e universidades revisitadas no início deste artigo. As implicações mutuas entre mercado de trabalho e formação superior permitem o fortalecimento de ambos com a abertura e manutenção tanto do campo quanto de cursos.

\subsection{NÍVEL DE CAPACITAÇÃO}

Sendo o arquivista o profissional formado no curso de Arquivologia, espera-se que os anúncios de emprego que buscam por esse profissional tenham conhecimento do ensino superior na área e que esse é o profissional ideal para gerir a documentação de uma instituição. O quadro 1 demonstra o nível de formação requerido pelas empresas que solicitam um profissional que atue junto à gestão documental. 
Quadro 1 - Nível de capacitação

\begin{tabular}{|c|c|c|c|c|}
\hline NÍVEL DE CAPACITAÇÃO & SITUAÇÃO & ÁREA & $\mathbf{F i}$ & $\%$ \\
\hline Ensino Fundamental & Completo & - & 2 & 0,98 \\
\hline \multirow{2}{*}{ Ensino Médio } & Completo & - & 48 & 23,41 \\
\hline & Cursando & - & 3 & 1,46 \\
\hline \multirow{15}{*}{ Ensino Superior } & \multirow{9}{*}{ Completo } & Administração & 5 & 2,43 \\
\hline & & Arquivologia & 29 & 14,15 \\
\hline & & Biblioteconomia & 17 & 8,29 \\
\hline & & Ciências Contábeis & 1 & 0,49 \\
\hline & & Direito & 1 & 0,49 \\
\hline & & Documentação & 2 & 0,98 \\
\hline & & Logística & 1 & 0,49 \\
\hline & & Serviço Social & 1 & 0,49 \\
\hline & & Não Especificado & 9 & 4,39 \\
\hline & \multirow{6}{*}{ Cursando } & Administração & 3 & 1,46 \\
\hline & & Arquivologia & 4 & 1,95 \\
\hline & & Biblioteconomia & 1 & 0,49 \\
\hline & & Ciências Contábeis & 2 & 0,98 \\
\hline & & Direito & 1 & 0,49 \\
\hline & & Não Especificado & 4 & 1,95 \\
\hline \multirow{2}{*}{ Ensino Técnico } & \multirow{2}{*}{ Completo } & Administração & 1 & 0,49 \\
\hline & & Arquivo & 7 & 3,31 \\
\hline Não informado & - & - & 63 & 30,73 \\
\hline Total & - & - & 205 & 100 \\
\hline
\end{tabular}

Fonte: Dados da Catho trabalhados pelos autores, 2017 a 2018.

No quadro apresentado, nota-se que a maior incidência nos anúncios de emprego foi identificado como "não informado". Assim, nesses 63 casos apenas a partir de contato direto com a contratante seria possível identificar o grau de capacitação requisitado.

Na sequência, com valores mais expressivos, encontraram-se os anúncios focados em empregados que exigiam ensino médio completo - com 48 incidências e caracterizando-se como $23,41 \%$ do total apresentado. É importante ter em mente os riscos e problemas decorrentes de uma contratação inadequada quando as organizações anunciam vagas para profissionais sem a capacitação adequada para trabalhar com a gestão dos documentos, que não possuem os aprendizados teóricos e práticos que um curso superior em Arquivologia proporciona. Ainda que recente e que o número de arquivistas não atenda a demanda social existente, sugere-se que sejam contratados profissionais com capacitações adequadas para a ocupação destas vagas, que por muito tempo foram atendidas pelos profissionais de Biblioteconomia. Neste caso, os bibliotecários apesar de não estudarem a especificidade dos documentos de arquivo, possuem conhecimentos correlatos aos da Arquivologia no que diz 
respeito à gestão da informação. Ainda que com valores não tão expressivos, a busca por profissionais com ensino fundamental e outras graduações também se caracteriza como um fator agravante, demonstrando que nem todas as contraentes têm conhecimento acerca do profissional adequado às atividades demandadas e anunciadas.

O ideal e coerente com as legislações e compreensão sobre o tratamento dado à gestão da informação e documental seria que o número dos que requisitam profissionais com formação em Arquivologia fosse maior. Das 205 incidências analisadas apenas 29 são para arquivistas, caracterizando-se como $14,15 \%$ do total. A conscientização das organizações contratantes consiste em uma parte fundamental neste processo. A desinformação é um empecilho que pode acarretar na contratação de indivíduos que não possuem a capacitação necessária para trabalhar na gestão documental de uma instituição.

O quadro 1 apresentado acima, ainda que soe como desestimulante ao graduando em Arquivologia, deve servir como alerta. Este panorama deve auxiliar para que estes futuros profissionais assumam um papel ativo na disseminação da profissão e em um marketing profissional adequado. É essencial mostrar que a capacitação profissional é fator chave ao trabalhar em um arquivo - não podendo ser executado por empregados não capacitados.

\subsection{HABILIDADES E COMPETÊNCIAS REQUERIDAS}

O mercado de trabalho de Arquivologia, assim como outras profissões que dialogam diretamente com a sociedade e suas mudanças, está em processo de capacitação e requer um conjunto de habilidade e competências cada vez maior. Através destas, é possível identificar a capacidade do profissional que se está contratando, com enfoque em melhorar as relações interpessoais e potencializar o desempenho dos funcionários de forma global dentro de uma organização. A busca pela redução de custos e o alcance de metas são pontos que refletem na necessidade de contratação de profissionais com uma ampla gama de habilidades e competências. Em uma sociedade cada vez mais criativa e inovadora, o arquivista precisa mostrar-se atualizado e com habilidades e competências desenvolvidas visando atender às necessidades de um mercado cada vez mais concorrido e exigente.

Dada esta importância, nesta subseção são apresentados os resultados referentes às habilidades e competências requeridas pelos anúncios de emprego analisados. Através do estudo, foram identificadas um total de 61 habilidades e 212 competências presentes nos 164 anúncios de empregos pesquisados. 
Apesar de subjetivo e variável, entre as empresas notou-se um padrão de algumas que habilidades, entre as quais, a organização, a proatividade e a responsabilidade como as três mais requeridas. A organização caracterizou-se como 12 incidências de um total de 61, representando 19,67\%. A responsabilidade e a proatividade possuíram 5 incidências cada e representaram $8,19 \%$ do total. Destacaram-se, ainda, a atenção, comunicação e liderança, cada uma com 4 incidências e representando $6,55 \%$.

Os anúncios também requeriam, ainda que com menor incidência, outras habilidades, entre elas: adaptabilidade, agilidade, assiduidade, colaboração, comprometimento, concentração, coordenação, detalhismo, dinamismo, disciplina, discrição, empatia, ética, gentileza, iniciativa, observação, presteza, relacionamento interpessoal, senso de prioridade e supervisão.

Atreladas às habilidades exigidas dos profissionais a serem contratados estão as competências requeridas. A seguir, o quadro 2 apresenta as competências requeridas pelas organizações contratantes dos anúncios analisados.

Quadro 2 - Competências requeridas

\begin{tabular}{|l|l|l|}
\hline COMPETÊNCIAS & Fi & \% \\
\hline Conhecimento avançado do pacote Office & 5 & 2,36 \\
\hline Conhecimento avançado em Excel & 7 & 3,30 \\
\hline Conhecimento básico do pacote Office & 16 & 7,55 \\
\hline Conhecimento básico em Excel & 2 & 0,94 \\
\hline Conhecimento básico em informática & 13 & 6,13 \\
\hline Conhecimento de arquivo de departamento de pessoal & 10 & 4,71 \\
\hline Conhecimento de arquivo financeiro & 11 & 5,19 \\
\hline Conhecimento de vocabulário controlado & 1 & 0,47 \\
\hline Conhecimento em arquivo jurídico & 3 & 1,41 \\
\hline Conhecimento em legislação arquivística & 2 & 0,94 \\
\hline Conhecimento em legislação trabalhista & 2 & 0,94 \\
\hline Conhecimento em programas de edição de imagem & 1 & 0,47 \\
\hline Conhecimento em redação empresarial & 1 & 0,47 \\
\hline Conhecimento em técnicas de oratória & 1 & 0,47 \\
\hline Experiência com arquivo morto & 1 & 0,47 \\
\hline Experiência com auditoria de prontuário & 1 & 0,47 \\
\hline Experiência com avaliação documental & 1 & 0,47 \\
\hline Experiência com digitalização de documentos & 2 & 0,94 \\
\hline Experiência com gestão eletrônica de documentos & 6 & 2,83 \\
\hline Experiência com recrutamento e seleção & 2 & 0,94 \\
\hline Experiência com recuperação da informação & 2 & 0,94 \\
\hline Experiência com sistema de protocolo & 1 & 0,47 \\
\hline Experiência como arquivista & 14 & 6,60 \\
\hline Experiência como bibliotecário & 1 & 0,47 \\
\hline & & \\
\hline
\end{tabular}




\begin{tabular}{|l|l|l|}
\hline Experiência em arquivo & 58 & 27,36 \\
\hline Experiência em arquivo hospitalar & 10 & 4,71 \\
\hline Experiência em registro hospitalar de câncer & 1 & 0,47 \\
\hline Experiência em classificação & 3 & 1,41 \\
\hline Experiência em construção civil & 1 & 0,47 \\
\hline Experiência em empresas do setor privado & 3 & 1,41 \\
\hline Experiência em entidades sem fins lucrativos & 1 & 0,47 \\
\hline Experiência em escritório de advocacia & 3 & 1,41 \\
\hline Experiência em escritório trabalhista & 1 & 0,47 \\
\hline Experiência em gestão de arquivos & 6 & 2,83 \\
\hline Experiência em indexação & 3 & 1,41 \\
\hline Experiência em liderança de pessoas & 1 & 0,47 \\
\hline Experiência em logística & 2 & 0,94 \\
\hline Experiência em órgãos públicos & 2 & 0,94 \\
\hline Experiência em setor de TI & 1 & 0,47 \\
\hline Experiência na área administrativa & 10 & 4,71 \\
\hline Total & $\mathbf{2 1 2}$ & $\mathbf{1 0 0}$ \\
\hline
\end{tabular}

Fonte: Dados da Catho trabalhados pelos autores, 2017 a 2018.

A experiência prévia em arquivo foi o maior destaque, com 58 incidências e 27,36\%, exigência esta que requer um profissional que já tenha tido algum contato com arquivo, independentemente do seu nível de capacitação exigido no anúncio. No entanto, a experiência como arquivista teve 14 incidências e 6,6\%. Neste caso torna-se imprescindível destacar a função dos estágios, que se caracterizam muitas vezes como o primeiro contato entre o graduando de Arquivologia e o mercado de trabalho. Através desta modalidade, o futuro arquivista pode conhecer os ambientes de atuação e aplicar aprendizados teóricos de modo a constituir uma parte vital na formação profissional e possibilitar o atendimento desta competência requisitada na hora de contratação.

Ainda que indicado separadamente no quadro, as competências exigidas quanto ao pacote Office (World, Excel, PowerPoint, OneNote, Outlook, Publisher e Access) totalizaram 30 incidências e $14,15 \%$ do total, ferramentas essas se podem ser aprendidas através de cursos de capacitação, tutoriais e prática. $\mathrm{Na}$ atualidade, as competências acerca de softwares e hardwares são facilitadas através do grande número de informações presentes na internet. Com 13 incidências e $6,13 \%$ das 212 competências requeridas, foi identificada a necessidade de um profissional com conhecimento básico em informática.

Alguns anúncios de emprego indicaram a necessidade não apenas de um profissional com experiência prévia com arquivo ou como arquivista, mas que conhecesse as especificidades do arquivo que deve ser trabalhado. Com 11 incidências e 5,19\% foi observado o conhecimento 
em arquivo financeiro e, não muito atrás, com 10 incidências e 4,71\%, anúncios que demandavam profissionais com experiências prévias em arquivo hospitalar e na área administrativa, tal como profissionais com conhecimento em arquivo de departamento de pessoal.

Apesar de verificadas competências requeridas nos anúncios com poucas incidências, destacou-se que o profissional deve estar atento para desenvolver conhecimentos, principalmente ligados à experiência prévia com arquivo ou como arquivista. Também foi identificada a necessidade de que o contratado conheça as especificidades dos diversos tipos de áreas de atuação e departamentos que constituem uma empresa, bem como desenvolver habilidades ligadas às novas tecnologias como a informática e o uso do pacote Office.

\subsection{ATIVIDADES A SEREM EXECUTADAS}

Os anúncios de empregos no portal Catho possuem um resumo de quais atividades serão executadas pelo contratado. Esta descrição prévia é essencial para que o contratado tenha conhecimento das tarefas das quais será responsável. Dentre os anúncios analisados, foram coletadas 667 atividades e apresentadas no quadro a seguir.

Quadro 3 - Atividades solicitadas pelas contratantes

\begin{tabular}{|l|l|l|}
\hline ATIVIDADE & Fi & $\mathbf{\%}$ \\
\hline Auditar prontuários médicos & 2 & 0,29 \\
\hline Assessorar outros departamentos & 23 & 3,45 \\
\hline Atender chamadas telefônicas & 7 & 1,05 \\
\hline Atender aos usuários & 40 & 5,99 \\
\hline Atuar com clipping de matérias jornalísticas & 1 & 0,15 \\
\hline Avaliar a documentação & 52 & 7,79 \\
\hline Capacitar à equipe & 4 & 0,59 \\
\hline Catalogar & 17 & 2,54 \\
\hline Classificar a documentação & 69 & 10,34 \\
\hline Conservar os documentos & 9 & 1,34 \\
\hline Controlar o acervo & 29 & 4,34 \\
\hline Dar suporte a biblioteca & 2 & 0,29 \\
\hline Descrever a documentação & 4 & 0,59 \\
\hline Despachar & 1 & 0,15 \\
\hline Digitalizar documentos & 44 & 6,59 \\
\hline Eliminar documentos & 4 & 0,59 \\
\hline Fazer gestão de documentos & 27 & 4,04 \\
\hline
\end{tabular}




\begin{tabular}{|l|l|l|}
\hline Fazer gestão eletrônica de documentos & 20 & 2,99 \\
\hline Fornecer cópia de prontuário & 5 & 0,74 \\
\hline Higienizar o acervo documental & 7 & 1,05 \\
\hline Indexar os documentos & 11 & 1,65 \\
\hline Microfilmar & 3 & 0,45 \\
\hline Ministrar aulas de Arquivologia para cursos preparatórios & 1 & 0,15 \\
\hline Ministrar treinamentos técnicos & 2 & 0,29 \\
\hline Organizar o acervo & 100 & 14,99 \\
\hline Padronizar os documentos & 14 & 2,09 \\
\hline Preservar a documentação & 18 & 2,69 \\
\hline Produzir documentos & 49 & 7,34 \\
\hline Protocolar & 44 & 6,59 \\
\hline Recolher documentação para o arquivo permanente & 10 & 1,49 \\
\hline Recuperar informações & 27 & 4,04 \\
\hline Registrar prontuários no sistema & 6 & 0,89 \\
\hline Restaurar documentação & 1 & 0,15 \\
\hline Transferir documentação para o arquivo intermediário & 11 & 1,65 \\
\hline Tratar os arquivos digitais & 3 & 0,45 \\
\hline Total & $\mathbf{6 6 7}$ & $\mathbf{1 0 0}$ \\
\hline
\end{tabular}

Fonte: Dados da Catho trabalhados pelos autores, 2017 a 2018.

Com o maior número de incidências a atividade de maior destaque foi a de organizar o acervo, com 100 resultados e 14,99\% dos resultados. O termo "organização" aparece no Dicionário Brasileiro de Terminologia Arquivística publicado pelo Arquivo Nacional (2005, p. 37) atrelado à Arquivologia e apresentado como "disciplina que estuda as funções do arquivo e os princípios e técnicas a serem observados na produção, organização, guarda, preservação e utilização dos arquivos". Apesar de um termo amplo, compreende-se que para a organização de um acervo torna-se necessária a aplicação de um conjunto de procedimentos e operações técnicas que, juntas, são responsáveis por tornar o acervo organizado.

A classificação documental apareceu logo a seguir com 69 incidências e 10,34\%, com proximidade da avaliação de documentos com 52 de frequência e 7,79\%. Ambos são procedimentos técnicos que caminham juntos e são essenciais ao tratar-se da organização de um acervo. Entre as concepções dadas à classificação, segundo o Arquivo Nacional (2005, p. 49), estão a de "organização dos documentos de um arquivo ou coleção, de acordo com um plano de classificação, código de classificação ou quadro de arranjo", "análise e identificação do conteúdo de documentos" e "atribuição a documentos, ou às informações neles contidas, de graus de sigilo, conforme legislação específica". A avaliação, por sua vez, consiste no processo de análise de documentos de arquivo, que estabelece os prazos de guarda e a destinação, de acordo com os valores que lhes são atribuídos. (ARQUIVO NACIONAL, 2005, p. 41). É 
compreensível que essas atividades relacionadas à noção de procedimentos iniciais a um acervo não ordenado previamente tenham destaque por serem essenciais para a gestão documental e representarem um caráter prioritário na contratação de um arquivista.

A produção documental foi é a quarta atividade com maior número de incidências, com 49 resultados e 7,34\%, seguida do protocolo com 44 e 6,59\%. Estes resultados indicam que as organizações possuem preocupação em produzir de modo correto os documentos e controlar as tramitações de sua documentação, bem como tornar possível a padronização dos documentos e possibilitar maior fluxo de informação durante os trâmites organizacionais.

$\mathrm{O}$ atendimento aos usuários, atividade comum nas organizações, teve 40 incidências e 5,99\%,. O termo "usuários", compreendido de forma ampla, abarca não apenas pessoas externas que têm direito a acessar alguns documentos quanto empregados de outros setores da própria empresa que dependem de uma gestão documental de qualidade para exercer suas atividades. Neste contexto, e considerando a compreensão atual adotada para o arquivo, este caracterizase como órgão de suporte diante da demanda dos integrantes da organização por informações qualificadas, que sejam prontamente recuperadas e ofereçam subsídios para a tomada de decisão, possibilitando, assim, a redução de custos para a organização. Esse papel estratégico que os documentos possuem na sociedade atual é um reflexo da competividade e acarreta na valorização da informação e da profissão.

Uma variedade de atividades, conforme apresentado no quadro 3, é requerida pelo mercado atual. Durante a sua formação, o futuro arquivista precisa se preparar para atender as demandas existentes e se capacitar para a execução das atividades necessitadas pelas contratantes da forma mais eficaz. E a universidade tem papel essencial ao ensinar o "saber fazer” através de disciplinas teórico-práticas que exercitem tais atividades.

\subsection{REGIME DE CONTRATAÇÃO}

O regime de contratação é parte fundamental de uma oferta de emprego por trata-se da maneira que o vínculo empregatício será estabelecido e quais direitos e deveres terá o empregado. Os tipos de regime de contratação que apareceram nos anúncios foram: CLT, Prestador de Serviços e Temporária. Ocorreram, também, a incidência de casos que não informavam o regime de contratação. 
A CLT caracterizou-se como 100 incidências e 61\% dos anúncios de emprego analisados. A Consolidação das Leis Trabalhistas (CLT) foi aprovada durante o mandato do Presidente Getúlio Vargas pelo Decreto-Lei 5.452, de $1^{\circ}$ de maio de 1943, e entre os direitos por ela regidos estão o de férias, o $13^{\circ}$ salário, descanso remunerado, salário mínimo, jornada de trabalho e a licença maternidade. A CLT passou por diversas mudanças durante os anos e ainda é alvo de propostas de alterações. A chamada "Reforma Trabalhista" foi a mais recente alteração promulgada por meio da Lei $\mathrm{N}^{0}$ 13.467, de 13 de julho de 2017, tendo como finalidade descrita em sua ementa: "a fim de adequar a legislação às novas relações de trabalho".

Nos resultados obtidos, 42 incidências e 25,6\% do total constituíram anúncios que não informaram o regime de contratação. Com 18 incidências e 11\% foram identificadas as contratações temporárias e, com apenas, 4 incidências e 2,4\%, os anúncios que possuíram como regime de contratação o prestador de serviços/pessoa jurídica (PJ).

\subsection{BENEFÍCIOS}

Os benefícios consistem em um diferencial ao escolher um emprego e sua análise contribui para a compreensão da remuneração e valorização dada ao profissional da área. Tendo em vista identificar os benefícios com maior frequência ofertados ao arquivista, analisou-se os seguintes:

Quadro 4 - Benefícios ofertados

\begin{tabular}{|l|l|l|}
\hline BENEFíCIO & Fi & \% \\
\hline Assistências Médica & 75 & 15,1 \\
\hline Assistência Odontológica & 45 & 9,05 \\
\hline Auxílio Creche & 4 & 0,8 \\
\hline Cesta Básica & 19 & 3,82 \\
\hline Convênio com Farmácia & 14 & 2,81 \\
\hline Estacionamento & 8 & 1,6 \\
\hline Estudo de Faculdade & 2 & 0,4 \\
\hline Participação nos Lucros & 8 & 1,6 \\
\hline Seguro de Vida em Grupo & 46 & 9,25 \\
\hline Seguro Saúde & 8 & 1,6 \\
\hline Tíquete Alimentação & 27 & 5,43 \\
\hline Tíquete Refeição & 93 & 18,71 \\
\hline Vaga para Deficiente & 20 & 4,02 \\
\hline Vale Transporte & 128 & 25,75 \\
\hline Total & $\mathbf{4 9 7}$ & $\mathbf{1 0 0}$ \\
\hline
\end{tabular}

Fonte: Dados da Catho trabalhados pelos autores, 2017 a 2018. 
Vale transporte e tíquete refeição foram identificados com maiores incidências entre os benefícios pagos, com respectivamente 128 e 93 anúncios e caracterizaram-se por $25,75 \%$ e $18,71 \%$ do total de ofertas recuperadas e analisadas da base de dados. O vale transporte relaciona-se à locomoção do empregado à empresa e o tíquete refeição com a promoção do horário de almoço. Ainda que identificados no portal como benefícios, o vale transporte é um direito previsto através da Lei $\mathrm{N}^{0} 7.619$, de 30 de setembro de 1987, que o institui "“[...] que o empregador, pessoa física ou jurídica, antecipará ao empregado para utilização efetiva em despesas de deslocamento residência-trabalho e vice-versa" e o tíquete refeição está previsto no art. 458 da CLT, Brasil (1943): "além do pagamento em dinheiro, compreende-se no salário, para todos os efeitos legais, a alimentação, habitação, vestuário ou outras prestações "in natura" que a empresa, por fôrça do contrato ou do costume, fornecer habitualmente ao empregado $[\ldots] "$

A assistência médica, com 75 incidências e 15,1\% caracterizou-se como o terceiro benefício com maior destaque, seguido do seguro de vida em grupo com 46 incidências e 9,25\% e assistência odontológica com 45 incidências e 9,05\%.

Existe uma gama de benefícios que podem ser ofertados ao empregado, de modo que o arquivista deve buscar o que melhor atende as suas necessidades e estar atento que alguns deles proporcionam adicionais no valor da remuneração.

\subsection{REMUNERAÇÃO}

Segundo o portal empresarial Catho, a média nacional de salário anunciado a área durante o período era de $\mathrm{R} \$ 1.265,30$. No entanto, dentre os anúncios analisados, o termo com maior incidência foi o "a combinar", com 79 e 48,18\%. Este dado colabora para a verificação acerca do papel do arquivista que deve estar preparado para negociar um salário, que esteja em equilíbrio com o valor remunerado pelo mercado e que reflita as atividades, atitudes, valores e habilidades colocadas em prática. O "a combinar" representa, neste contexto, a possibilidade de conscientização sobre a área e sobre a importância do arquivista enquanto um dos responsáveis pelo marketing profissional e a influência no salário a ser estabelecido junto a contratante.

Dentre os valores descrito, a faixa salarial de R\$ 1.001,00 a 1.990,00 apareceu em segundo lugar com uma frequência de 65 resultados e 39,60\% do total. Esta faixa salarial é 
compatível com média de $\mathrm{R} \$ 1.265,30$ apresentada pelo portal empresarial Catho para o período da pesquisa.

Com menores incidências, foram identificadas as faixas salariais de até R\$1000,00 com 8 anúncios e 4,88\%, e a faixa salarial de $\mathrm{R} \$ 1.991,00$ a 2.9990,00 com 7 resultados e $4,27 \%$. As faixas salariais com valores de remuneração mais altos foram as de menor tem incidência, correspondendo a 2 de $\mathrm{R} \$ 2.991,00$ a 3.990,00 e 3 com remunerações acima de $\mathrm{R} \$$ $3.991,00$.

A menor remuneração registrada no período de pesquisa no portal para o cargo de arquivista foi de $\mathrm{R} \$ 968,00$, superior ao valor de $\mathrm{R} \$ 954,00$ correspondente ao do salário mínimo após o reajuste anual de 2018. Ainda que acima, não significa que seja um dado positivo, visto que este profissional de nível superior, que demandou investimento em sua formação e cujas atividades trazem diversos benefícios, inclusive financeiros, para uma organização, deveria ter uma maior valorização em relação ao salário mínimo da época analisada.

Em contrapartida, o maior valor anunciado foi de $\mathrm{R} \$ 7.000,00$, mas que se tratou de um único caso. Além desse valor, o segundo mais alto foi de $\mathrm{R} \$ 4.500,00$. A discrepância entre o menor e o maior valor ofertados não pode ser analisada sem mais informações, como carga horária, ou adicionais não descritos no anúncio como poderia ser o caso da insalubridade. Mas esta diferença deve, sim, servir como alerta para se pensar a valorização e coerência na hora de negociações de salários iniciais.

\section{CONSIDERAÇÕES FINAIS}

O desenvolvimento do mercado de trabalho dos arquivistas é constante. As legislações, a cultura e as tecnologias são fatores chave na expansão e modelações deste mercado. A sociedade atual demanda informações qualificadas e que sejam recuperadas em uma velocidade cada vez maior. Esta crescente necessidade relaciona-se diretamente à competividade das organizações, que buscam continuamente a melhoria de seus processos com enfoque na redução de custos.

O uso das tecnologias é um ponto fundamental ao tratar-se do mercado de trabalho atual, visto a crescente demanda por profissionais que tenham conhecimentos de informática e 
que saibam utilizar softwares que auxiliem em suas atividades. Dentre as atividades arquivísticas que possuem auxiliares digitais encontram-se: digitalizar documentos, fazer a gestão eletrônica de documentos, utilizar sistemas específicos para o registro de documentos, bem como tratar os arquivos digitais. Tais atividades aparecem com frequência nos anúncios de emprego, demonstrando que os arquivistas precisam aprender, exercitar e aprimorar o conhecimento sobre as tecnologias que estão a sua disposição.

Apesar das diversas reflexões que a pesquisa aqui apresentada proporcionou e ainda pode vir a proporcionar, um dos intuitos iniciais foi verificar as demandas por arquivistas e as competências solicitadas para a sua atuação, tendo como permitindo identificar pontos a serem melhorados no relacionamento entre universidade e sociedade. Neste contexto, a universidade representa parte crucial na conscientização das organizações para que contratem profissionais com habilitações necessárias para exercer as atividades demandadas, bem como e na capacitação de profissionais que atendam às necessidades de uma sociedade tecnológica, inovadora e criativa, que valoriza profissionais que trabalhem em equipe, que sejam organizados, tenham responsabilidade, senso de liderança e estejam atentos ao seu meio social e suas modificações.

Dos resultados obtidos conclui-se que, dos meses pesquisados, o que possuiu maior número de anúncios de empregos registrados no portal Catho, foi o mês de janeiro. Este dado sugere que as organizações buscam começar o ano com renovação e aplicação de novas políticas. Dos 164 anúncios analisados, o Sudeste representou a região do Brasil com o maior número de ofertas de emprego, com 118 anúncios. O Estado de São Paulo foi o que representou maior número de anúncios, sendo 82, e a cidade de São Paulo, 57. Este comportamento é reflexo desta capital ser é o maior centro urbano brasileiro e comportar um alto número de empresas, instituições e organizações dos diversos ramos de atuação.

O nível de capacitação requerido pelas contratantes é um fator preocupante. Durante o período de pesquisa foi identificada a grande procura por empregados que possuíssem ensino fundamental, médio e superior (neste caso, em áreas de atuação que não sejam a Arquivologia). Isto serve de alerta para que os arquivistas estejam preparados para conscientizar as contratantes sobre a existência do curso de graduação em Arquivologia e que este é o profissional habilitado para executar de forma efetiva as atividades requeridas.

As empresas - de diversos ramos de atuação - buscam cada vez mais uma variedade de habilidades e competências dos profissionais a serem contratados, descrevendo em seus anúncios uma quantidade diversificada de atividades a serem realizadas. Assim, os profissionais 
da área necessitam buscar atualização constante e estarem atentos às demandas do mercado de trabalho, com objetivo de desenvolver habilidades e competências que são requeridas da forma mais eficiente possível.

Das vagas anunciadas e analisadas na pesquisa, o regime de contratação mais comum foi a CLT. Benefícios também foram identificados como ofertados aos contratados, com maior destaque para o vale transporte e o tíquete refeição, que possuíram o maior número de incidências. A remuneração resgatada variou de $\mathrm{R} \$ 968,00$ a $\mathrm{R} \$ 7.000,00$, com uma ressalva para os anúncios que apresentaram o termo "a combinar" e que tiveram maior incidência casos em é possível o arquivista negociar o valor salarial. Como parte da busca por uma colocação no mercado de trabalho, o profissional não deve estar atento apenas às demandas, mas também à remuneração, para que consiga um salário consoante com a realidade nacional e com a valorização que deve receber.

Comumente, profissões, quando instituídas ou organizadas, inicialmente apresentam resistências no mercado de trabalho - muitas vezes por desconhecimento da sociedade e das empresas com potencial para tornaram-se contratantes. Desbravar estes caminhos é um esforço coletivo do qual o acadêmico não pode se esquivar. É por meio de iniciativas como, por exemplo, a abertura de novos espaços de estágio, que a atuação do arquivista conquista valorização e conscientiza as organizações. As universidades precisam fornecer as ferramentas e colaborar na abertura de espaços, mas os acadêmicos e egressos precisam aprender a fazer o marketing pessoal e profissional para que o arquivista possa, progressivamente, ocupar o lugar que merece e que a sociedade precisa. 


\section{REFERÊNCIAS}

ARQUIVO NACIONAL (Brasil). Dicionário brasileiro de terminologia arquivística. Rio de Janeiro: Arquivo Nacional, 2005. 232 p. Disponível em: $<$ http://arquivonacional.gov.br/images/pdf/Dicion_Term_Arquiv.pdf $>$. Acesso em: 10 jun. 2018.

BAHIA, E. M. dos S. EI mercado de trabajo para archiveros según los anuncios brasileños de empleo (2012-2014): análisis y organización terminológicos de ofertas empresariales. 2016. 577 f. Tesis (Doctorado em Documentación: Archiveros y bibliotecas en el entorno digital) Universidad Carlos III de Madrid, Departamento de Biblioteconomía y Documentación, Madrid, 2016. Disponível em: <http://www.bu.ufsc.br/teses/ES0052-T.pdf $>$. Acesso em: 20 abr.

2019.

BAHIA, E. M. dos S.; MOREIRO-GONZÁlEZ, J. A. Archivos y documentalistas empreendedores: el caso español y brasileño. Informação \& Sociedade: estudos, v. 24, n. 2, p. 121-138, maio/ago. 2014. Disponível em: $<$ http://www.ies.ufpb.br/ojs2/index.php/ies/article/view/16539/11538>. Acesso em: 20 abr. 2019.

BAHIA, E. M. dos S.; MOREIRO-GONZÁLEZ, J. A. Oferta de emprego: habilidades necessárias para Arquivistas em empresas no Brasil. Informação \& Informação, v. 24, n. 1, p. 424.441, jan./abr. 2019. Disponível em: $<$ http://www.uel.br/revistas/uel/index.php/informacao/article/view/30419>. Acesso em: 20 maio 2019.

BRASIL. Decreto 82590/78. Regulamenta a Lei $n^{0}$ 6.546, de 4 de julho de 1978, que dispõe sobre a regulamentação das profissões de Arquivista e de técnico de Arquivo. Disponível em: $<$ http://planalto.gov.br/ccivil_03/decreto/1970-1979/d82590.htm>. Acesso em: 1 abr. 2018.

BRASIL. Decreto-Lei 5452/43: Aprova a Consolidação das Leis do Trabalho. Disponível em: $<$ http://planalto.gov.br/ccivil_03/decreto-lei/Del5452.htm>. Acesso em: 28 maio 2018.

BRASIL. Lei 6546/78: Dispõe sobre a regulamentação das profissões de Arquivista e de Técnico de Arquivo, e dá outras providências. Disponível em: $<$ http://planalto.gov.br/ccivil_03/leis/1970-1979/16546.htm>. Acesso em: 1 abr. 2018.

BRASIL. Lei 7619/87: Altera dispositivos da Lei $\mathrm{n}^{\mathrm{o}}$ 7.418, de 16 de dezembro de 1985, que instituiu o vale-transporte. Disponível em: $<$ http://www.planalto.gov.br/ccivil_03/Leis/L7619.htm>. Acesso em: 28 jun. 2018.

BRASIL. Lei 8159/91: Dispõe sobre a política nacional de arquivos públicos e privados e dá outras providências. Disponível em: <http://planalto.gov.br/CCIVIL_03/Leis/L8159.

$\begin{array}{lllll}\mathrm{htm}> & \text { Acesso } & \mathrm{em}: & 1 & \mathrm{abr} .\end{array}$

BRASIL. Lei 13467/17: Altera a Consolidação das Leis do Trabalho (CLT), aprovada pelo Decreto-Lei no 5.452, de 1 o de maio de 1943, e as Leis nos 6.019, de 3 de janeiro de 1974, 8.036, de 11 de maio de 1990, e 8.212, de 24 de julho de 1991, a fim de adequar a legislação às novas relações de trabalho. Disponível em: <http://planalto.gov.br/ccivil_03/_ato2015- 
CATHO. Guia de profissões. Disponível em: <http://catho.com.br/profissoes/arquivista $>$. Acesso em: 5 abr.

2018.

CATHO. Catho. Disponível em: <http://catho.com.br>. Acesso em: 5 abr. 2018.

CONARQ. Cursos de Arquivologia no Brasil. Disponível em: $<$ http://conarq.arquivonacional.gov.br/links-uteis/389-cursos-de-Arquivologia-nobrasil.html . Acesso em: $10 \quad$ jun. 2018 .

GAGNON-ARGUIN, Louise. Os arquivos, os arquivistas e a arquivística. In: ROSSEAU, JeanYves; COUTURE, Carol (Org.). Os fundamentos da disciplina arquivística. Lisboa: Publicações Dom Quixote, 1998.

MOREIRO-GONZALEZ, J. A.; VERGUEIRO, W. de C. S.; SÁNCHEZCUADRADO, S. Análise do contexto de emprego dos profissionais brasileiros da Informação-Documentação a partir de ofertas de trabalho na Web feitas por empresas e instituições. Informação \& Sociedade: estudos, v. 22, n. 1, p. 67-78, 2012. Disponível em: $<$ http://www.ies.ufpb.br/ojs2/index.php/ies/article/view/9747>. Acesso em: 20 abr. 2019.

MOREIRO GONZALEZ, J. A.; VERGUEIRO, W. de C. S. Ofertas de trabalho na Web para os profissionais brasileiros da informação-documentação: análise das competências e habilidades exigidas pelas empresas e instituições. Perspectivas em Ciências da Informação, Belo Horizonte, v. 17, n. 1, p. 231-250, jan./mar. 2012. Disponível em: $<$ http://www.scielo.br/pdf/pci/v17n1/a13v17n1.pdf $>$. Acesso em: 20 abr. 2019.

SANTANA, Marco Aurélio. O mundo do trabalho em mutação: as reconfigurações e seus impactos. Cadernos IHU Idéias, v.3, n.34, 2005. Disponível em: $<$ http://ihu.unisinos.br/images/stories/cadernos/ideias/034cadernosihuideias.pdf $>$. Acesso em: 23 abr. 2018. 